\title{
DETERMINATION OF NITRAZEPAM IN PHARMACEUTICAL PREPARATIONS USING SOLID-PHASE REACTOR - REVERSE FLOW INJECTION ANALYSIS
}

\author{
Mariam Jamal, Hind Hadi* \\ Department of Chemistry, College of Science, University of Baghdad, Jadriyah, Baghdad, Iraq. Email: hindhadi13@yahoo.com
}

Received: 21 March 2018, Revised and Accepted: 11 April 2018

\begin{abstract}
Objective: A simple and fast reverse flow injection system including a solid-phase reactor containing $\mathrm{PbO}_{2}$ with spectrophotometric detection was suggested for the determination of nitrazepam (NIT) in pharmaceutical tablets.
\end{abstract}

Methods: The method was based on oxidation of the reagent (phloroglucinol) with $\mathrm{PbO}_{2}$ immobilized in a polymeric matrix which was then coupled with reduced NIT in aqueous medium. The pink-colored product was measured at $530 \mathrm{~nm}$.

Results: The calibration graph was linear over the range of $50-400 \mu \mathrm{g} / \mathrm{mL}$ with a relative standard deviation of $<2 \%$ (n=29) and a sample throughput of 48 samples per hour. The variables of the solid-phase reactor such as composition, particle size, and length of the reactor were studied. The chemical and physical parameters, which affect the reverse flow method, were also studied.

Conclusion: The oxidation reactor engaged with a flow system was successfully applied for the determination of NIT with good sensitivity and precision.

Keywords: Reverse flow injection, Nitrazepam, Solid-phase reactor.

(C) 2018 The Authors. Published by Innovare Academic Sciences Pvt Ltd. This is an open access article under the CC BY license (http://creativecommons. org/licenses/by/4. 0/) DOI: http://dx.doi.org/10.22159/ajpcr.2018.v11i7.26644

\section{INTRODUCTION}

Nitrazepam (NIT) (7-nitro-5-phenyl-1,3-dihydro-2H-1,4-benzodiazepin-2-one, $\mathrm{C}_{15} \mathrm{H}_{11} \mathrm{~N}_{3} \mathrm{O}_{3}$ ) is a hypnotic agent that has been mainly effective in the treatment of difficulty of falling asleep, early awakening, or a combination of each and sometimes used for intractable epilepsies [1]. Different methods have been reported in the literature for the estimation of NIT in pharmaceutical and biological samples. Recent studies include a chemiluminescent method [2], reverse-phase high-pressure liquid chromatography (HPLC) [3], mass spectroscopy [4], liquid-liquid microextraction followed by HPLC [5], capillary electrophoresis [6], and thinlayer chromatography [7]. Among the different techniques, the spectrophotometric and flow injection analysis methods considered as most popular and simple methods existing for quick and trace analysis of drugs [8-13]. Solid-phase reactor (SPR) engaged with flow system was suggested previously for the determination of different drugs [14] using $\mathrm{PbO}_{2}$ immobilized on inert support as an oxidant. This kind of reactor (oxidant reactor) was adopted for the determination of NIT in dosage forms using single line flow injection manifold.

A sensitive pink-colored product, which gave a highest absorbance at $530 \mathrm{~nm}$, was appeared directly after addition of oxidized phloroglucinol (PHG) to our target reduced drug (NIT) during the oxidative coupling reaction. The reaction between NIT and PHG was adopted to develop a new flow injection method using an oxidant reactor loaded with $\mathrm{PbO}_{2}$ immobilized on cellulose acetate (CAC).

\section{METHODS}

\section{Apparatus}

A digital double beam spectrophotometer (Shimadzu, ultraviolet [UV] visual 260) was used in all absorbance measurements. A $50 \mu \mathrm{L}$ internal volume flow cell (FC) and a peristaltic pump (Ismatec,
CH8152, Zurich, Switzerland) were used to pump the solutions through flexible vinyl tubing ( $0.5 \mathrm{~mm}$ i.d.). An injection valve (IV) (Rheodyne, Altex 210, Supelco, USA) provided with variable volumes for injecting the standard solutions or the samples. The IV and the FC were connected through a Teflon reaction coil (RC) $(0.5 \mathrm{~mm}$ i.d.). The reverse flow manifold contained a single channel (Fig. 1). Through the IV, PHG was injected into the stream of reduced NIT solution which was then oxidized through the $\mathrm{PbO}_{2} \mathrm{SPR}(5.5 \mathrm{~cm}$, with a particle size of $1 \mathrm{~mm}$ ) and then mixed in a $50 \mathrm{~cm}$ RC. The stream of solution was propelled at a flow rate of $1 \mathrm{~mL} / \mathrm{min}$ using the peristaltic pump, and finally, the absorbance of the product was then detected at $530 \mathrm{~nm}$.

\section{Materials and reagents}

The reagent grade materials were used throughout this work. NIT, the working standard, was kindly supplied by the State Company for Drug Industries and Medical Appliances (SDI), Samarra, Iraq. Pharmaceutical formulations (Zipex® $5 \mathrm{mg}$, Aburaihan Pharmaceutical Co., Tehran, Iran, and Mogam ${ }^{\circledR} 5 \mathrm{mg}$, Domina Pharmaceuticals, Syria) were obtained from local markets. PHG (British Drug Houses, UK), lead (IV) dioxide (Merck, Chemicals Ltd., Germany), CAC (BDH Chemicals Ltd., Poole, England), hydrochloric acid (BDH), N,N-Dimethyl formamide (BDH), zinc powder (Fluka, Buchs, Switzerland), and acetone (BDH) were used.

\section{Preparation of standard stock solutions (NIT solution)}

The reduction solution of NIT was prepared by dissolving $0.0500 \mathrm{~g}$ of NIT in $50 \mathrm{~mL}$ of ethanol. This solution then transferred into a beaker and then added a $20 \mathrm{~mL}$ of distilled water, $20 \mathrm{~mL}$ of $11.65 \mathrm{~N}$ hydrochloric acid, and $3.0 \mathrm{~g}$ of zinc powder. The mixture allowed to stand for about $15 \mathrm{~min}$ at room temperature $\left(25^{\circ} \mathrm{C}\right)$. The solution was filtered into a $100 \mathrm{~mL}$ volumetric flask, and the residues were washed and diluted to the mark with distilled water. Simple dilution was used daily for prepared more diluted solutions. 
PHG solutions ( $0.1 \mathrm{M})$

These solutions were daily prepared by dissolving $1.2611 \mathrm{~g}$ of PHG into $100 \mathrm{~mL}$ of distilled water and then transferred into brown bottles. The more dilute solution was prepared by suitable dilution with distilled water.

\section{Preparation of $\mathrm{PbO}_{2} \mathrm{SPR}$}

The procedure of immobilizing $\mathrm{PbO}_{2}(\mathrm{~s})$ onto an inert support that was reported previously [15] was adopted in this work. We dissolved $0.5 \mathrm{~g}$ of CAC dissolved in $0.5 \mathrm{~mL}$ dimethylformamide and $3 \mathrm{~mL}$ of acetone, with continuous stirring, and then, $4 \mathrm{~g}$ lead dioxide powder was added gradually to the solution. Continuous manually stirring was used for homogenized mixture until viscosity was increased. Then, the homogenous mixture was washed with distilled water, and a rigid polyester was attained and left to air dry. The polyester, which contains the immobilized $\mathrm{PbO}_{2}$, was cut with scissors into approximately $1 \mathrm{~mm}$ particles. Then, polyester particles were then packed into glass tubes (lengths of $2 \mathrm{~mm}$ i.d.). To hold the particles inside the tubes, a small pieces of sponge were inserted into the ends of tubes.

\section{Preparation of NIT tablets solution}

Approximately 20 tablets were accurately weighed and powdered. Then, an amount of powder equivalent to $50 \mathrm{mg}$ of NIT was dissolved in approximately $30 \mathrm{~mL}$ of ethanol. This solution was filtered into a $50 \mathrm{~mL}$ volumetric flask and then washed and diluted to the mark with ethanol to obtain $1000 \mu \mathrm{g} / \mathrm{mL}$ of NIT. The resultant solution was transferred into $125 \mathrm{~mL}$ beaker and was reduced as described above. The appropriately diluted solutions of the pharmaceutical formulations were made with distilled water

\section{RESULTS AND DISCUSSION}

\section{Preliminary studies}

The absorption spectra of the product and the blank were obtained manually before automating the reaction by performing the reaction in a $25-\mathrm{mL}$ volumetric flask. A $50 \mu \mathrm{g} / \mathrm{mL}$ concentration of reduced NIT, $2 \mathrm{~mL}$ of $0.02 \mathrm{M}$ of $\mathrm{PHG}$, and $0.1 \mathrm{~g}$ of immobilized $\mathrm{PbO}_{2}$ was mixed and swirled and the pink-colored product was formed immediately. The flasks were made up to the mark with water and then filtered. The absorption spectra were recorded (after $3 \mathrm{~min}$ from filtration) between 400 and $750 \mathrm{~nm}$. The maximum value of absorption was measured at $530 \mathrm{~nm}$ versus the reagent blank (Fig. 2).

After studying the reaction stoichiometry of reaction in a batch method using an equimolar concentration of NIT and PHG and applying the mole ratio method, it was found that a 1:1 NIT: PHG ratio was obtained under this reaction. (Reduced NIT due to its strong electron donating ability couples with PHG after oxidized by $\mathrm{pbO}_{2}$, and the proposed mechanism of the coupling product is shown in Scheme 1 [16].

\section{Optimization of the chemical and physical conditions}

Before starting the first injection, the reactor was conditioned previously by pumping the carrier solution for $10 \mathrm{~min}$, to decrease the effect of particle compaction in the reactor on the absorbance value. Reduced NIT was propelled by a peristaltic pump, and the reagent (PHG) was injected 3 times for each experiment.

\section{Effect of the FIA system and manifold}

The flow system used in this work is reverse flow system rather than normal system to increase the "life-span" of the reactor [14] by minimizing the consumption of the oxidants immobilizing on the CAC support as a result of continuous merging of reagent (PHG) through the reactor. Different reaction manifolds were examined to obtain different reaction paths using distilled water or acid as a carrier. It was clear from the results that the manifold in Fig. 1 gave the best absorbance and good reproducibility and was thus chosen for further use. The optimum rFIA manifold contained a single-channel. PHG was injected inside the stream of the reduced drug solution using the IV, which was then oxidized by SPR-PbO and then mixed in the RC. Finally, the absorbance product was measured at $530 \mathrm{~nm}$ through the detector.

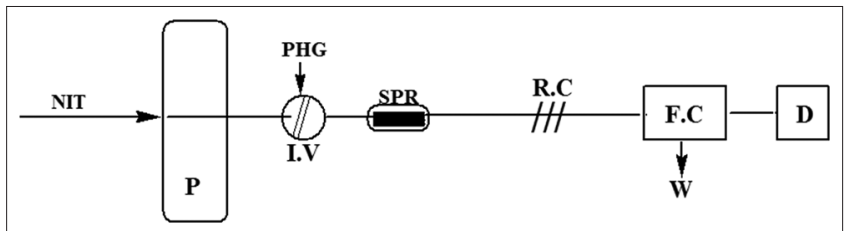

Fig. 1: A schematic diagram of the rFIA manifolds. p: Peristaltic pump, IV: Injection valve, RC: Reaction coil, FC: Flow cell, D: Detector, SPR: Solid phase reactor, W: Waste

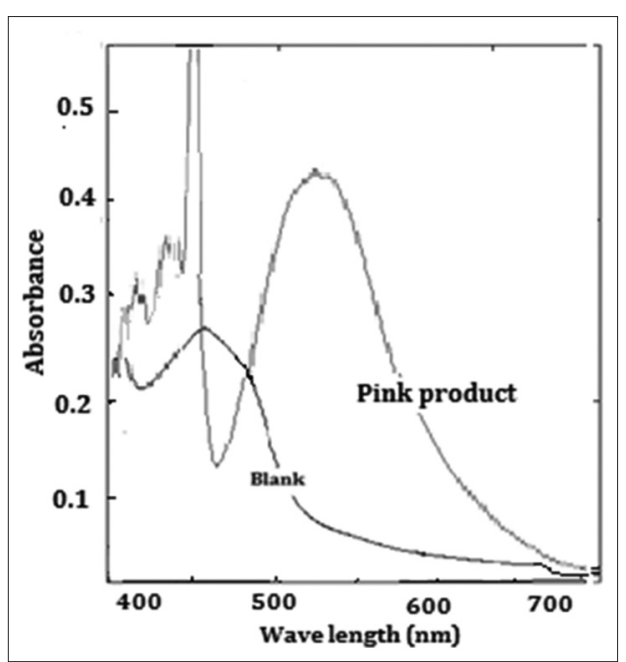

Fig. 2: The absorption spectra of $40 \mu \mathrm{g} / \mathrm{mL}$ of nitrazepam measured against the reagent blank, as well as the reagent blank measured against distilled water

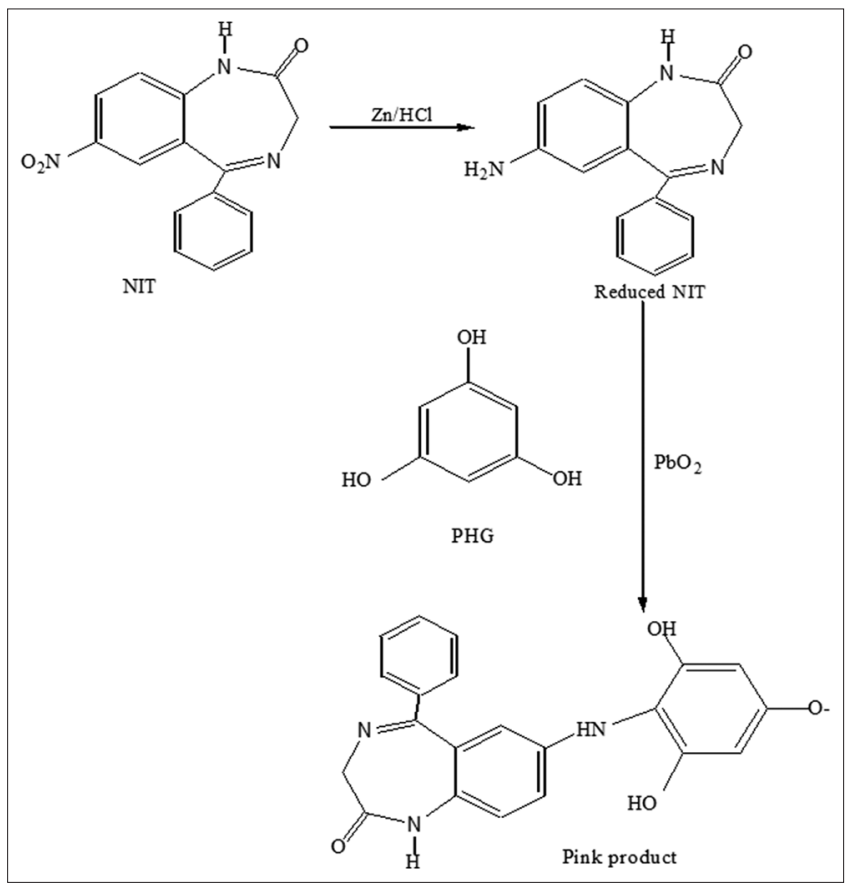

Scheme 1: Proposed mechanism of the reaction between nitrazepam and phloroglucinol

Optimization of solid-phase reactor variables

Effect of solid-phase type

Three different types of solid phase $\left(\mathrm{PbO}_{2}, \mathrm{MnO}_{2}\right.$, and $\mathrm{PbO}_{2}$ mixed with $\mathrm{TiO}_{2}$ ) were studied and examined. The results showed that the $\mathrm{PbO}_{2}$ SPR gave the best absorbance compared to the other reactors and was used in all later experiments (Fig. 3). 


\section{Solid-phase reactor composition ratio}

The effect of solid-phase components (the amount of $\mathrm{PbO}_{2}$ versus the inert support (AC) was established. Different $\mathrm{PbO}_{2}$ : $\mathrm{CAC}$ ratios "4:0.25, 4:0.5, 2:0.25, and 6:0.25 (w: w, g)" were examined (Fig. 4). The results show that the ratio of 4:0.5 provided the maximum absorbance and good precision.

The amount of supported component (CAC) is very important. Using a very small amount must be avoided to ensure efficient immobilization of oxidant onto the inert support and to reduce the partial solubility of immobilized $\mathrm{PbO}_{2}$ during the continuous flow of solution which affects the repeatability and lifespan of the reactor.

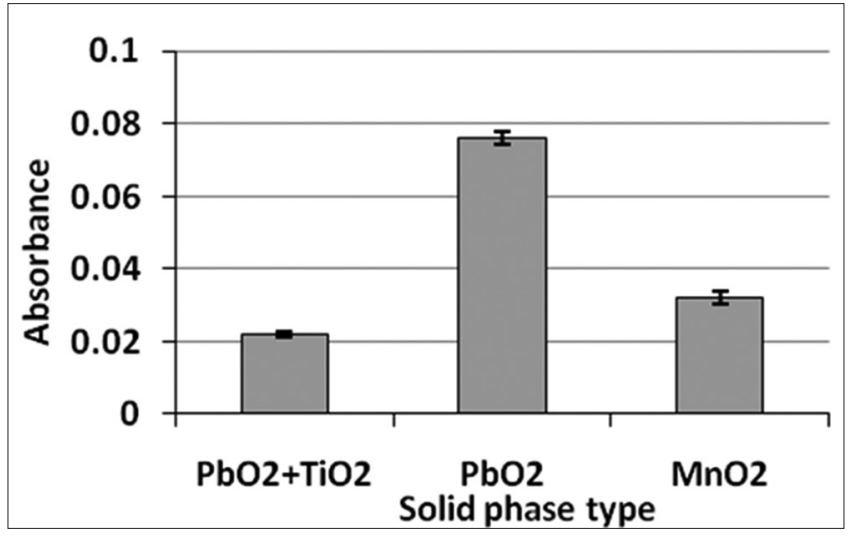

Fig. 3: Effect of solid-phase reactor type

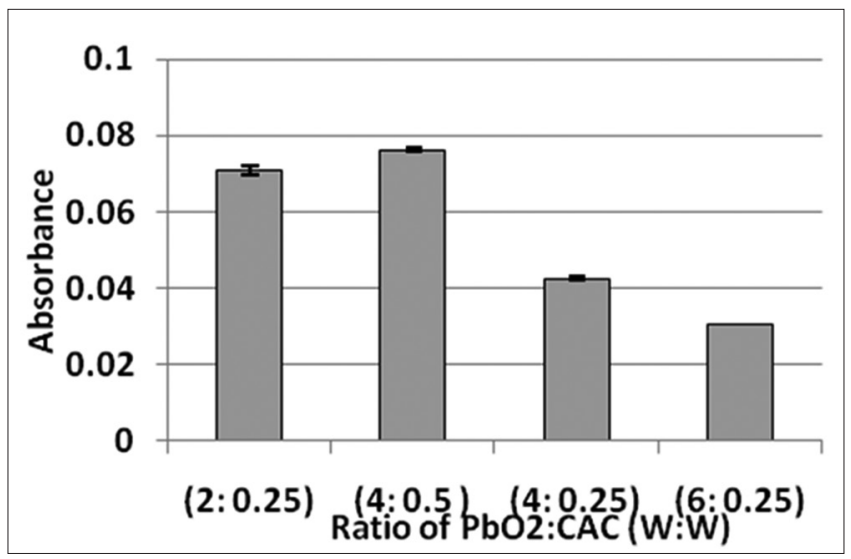

Fig. 4: Effect of solid-phase compositions

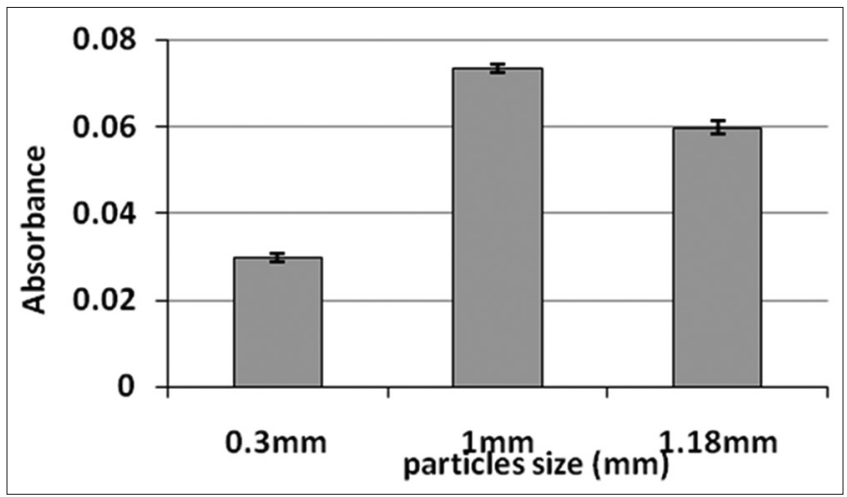

Fig. 5: Effect of the size of solid-phase particles (relative standard deviation for $\mathrm{n}=5$ )

\section{Solid-phase particle size}

Different sized particles in the range of 0.3-1.18 $\mathrm{mm}$ were examined (in this experiment, all the reactors were filled with different sized particles that had the same weight of 0.1660 g). The results (Fig. 5) showed that $1 \mathrm{~mm}$ particle size gave the maximum absorbance with good precision. Using different sizes but at the same weight caused differences in reactor packing. The large-sized particles would pack and arrange along the reactor more so than the small-sized particles, leading to the development of extra spaces over time in the case of small particles. With these spaces, ordinary dispersion was increased.

Length of the solid-phase reactor

The length of reactor was also studied in a range of $4.5-8 \mathrm{~cm}$. The absorbance value was increased with an increase of reactor length (Fig. 6) up to $5.5 \mathrm{~cm}$, and then, the signal decreased. A reactor of length

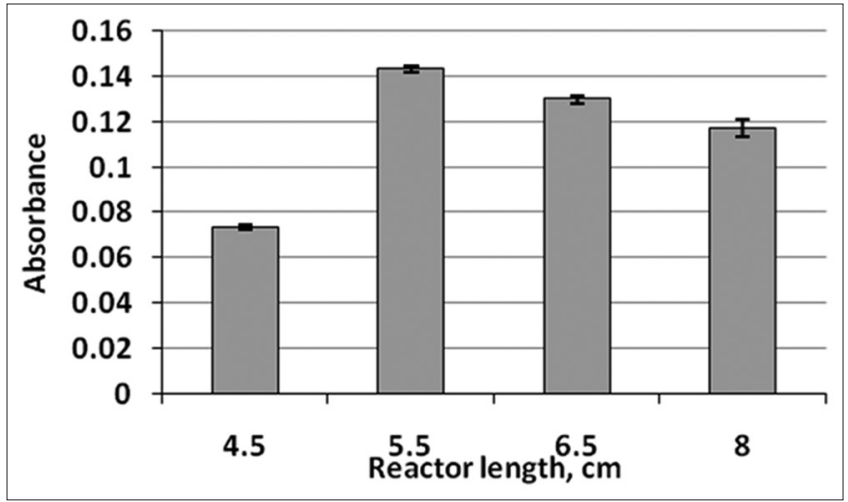

Fig. 6: Effect of the length of the solid-phase reactor

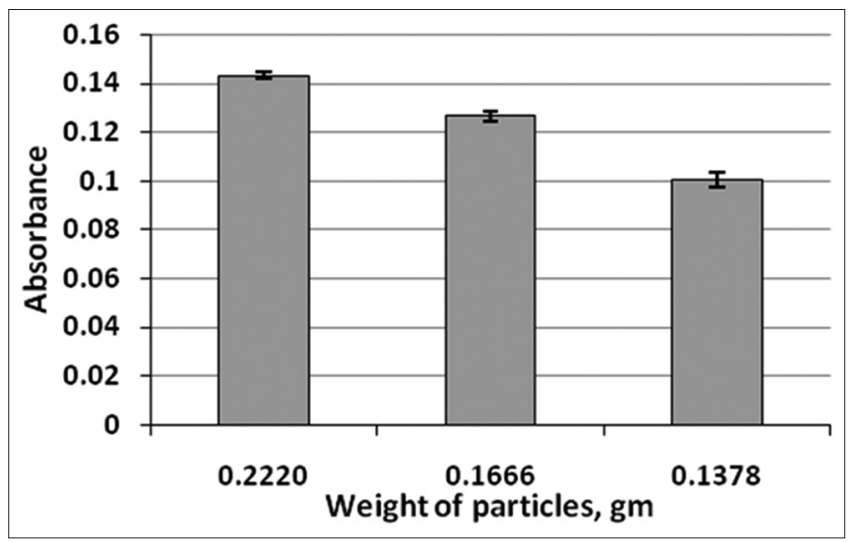

Fig. 7: Effect of the degree of packing in the reactor (relative standard deviation, $\mathrm{n}=5$ )

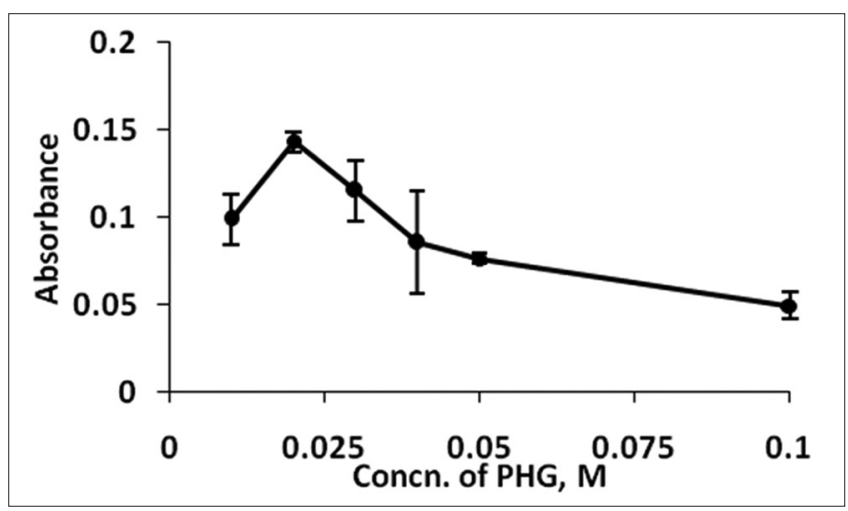

Fig. 8: Effect of phloroglucinol concentration 
$>5.5 \mathrm{~cm}$ showed baseline instability and bad precision; therefore, a reactor length of $5.5 \mathrm{~cm}$ was selected as it gave high absorbance with good reproducibility.

\section{Degree of packing}

In general, strong packing of material in the SPR (more than $0.222 \mathrm{~g}$ in this case) must be avoided to minimize resistance against the flowing solution propelled by the peristaltic pump during the reaction. The degree of packing (the optimum was $5.5 \mathrm{~cm}$ length and $1 \mathrm{~mm}$ size) was studied using different amounts of $\mathrm{PbO}_{2}$ immobilized on CAC. The obtained results (Fig. 7) show that $0.2220 \mathrm{~g}$ of the solid polymer gave a good packing and the highest absorbance.

\section{Optimization of chemical and physical variables}

\section{Effect of PHG concentration}

The optimum concentration of PHG was examined between 0.01 and $0.1 \mathrm{M}$. The results in Fig. 8 indicate that the concentration of $0.02 \mathrm{M}$

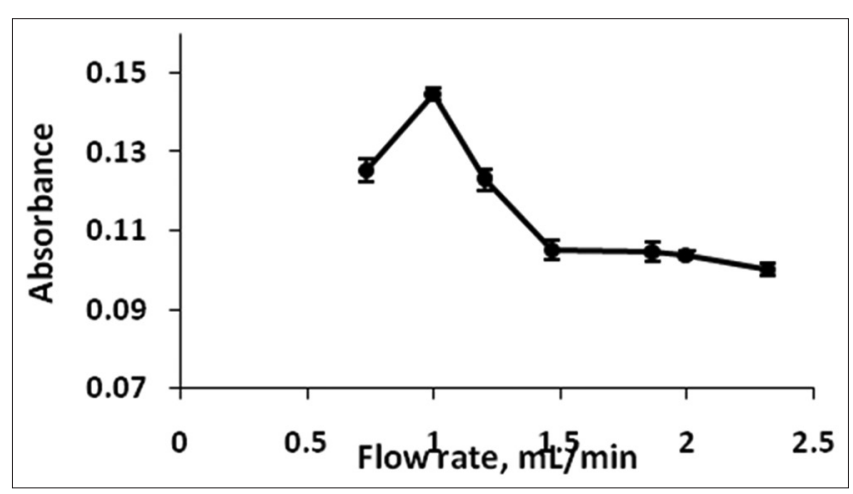

Fig. 9: Effect of total flow rate

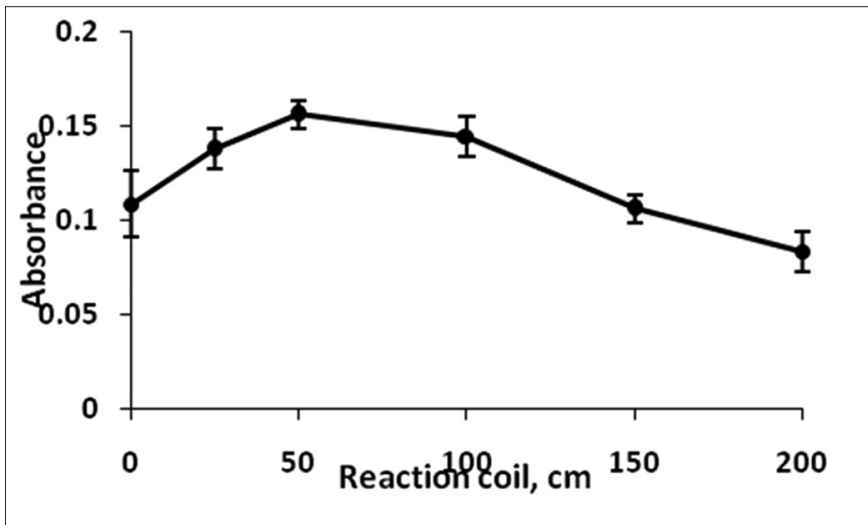

Fig. 10: Effect of the reaction coil length

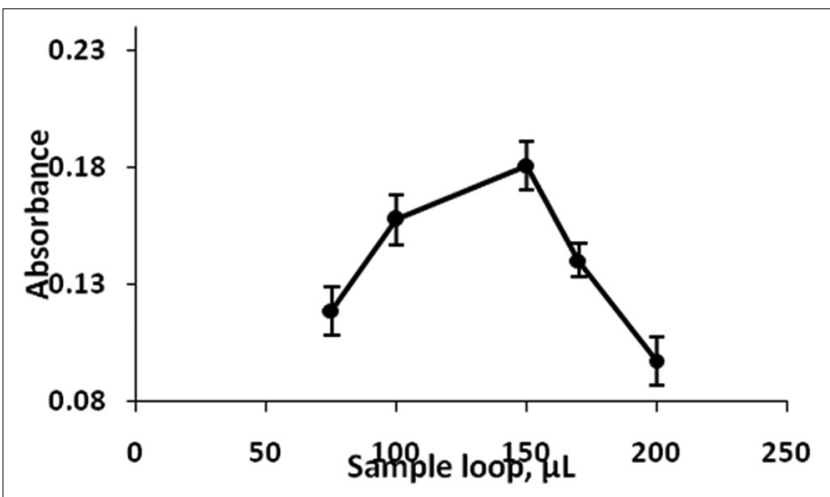

Fig. 11: Effect of injected sample volume gave the maximum absorbance and good precision and was thus chosen as optimum one.

\section{Effect of the total flow rate}

The flow rate was also studied between 0.73 and $2.32 \mathrm{~mL} / \mathrm{min}$. As the flow rate increased, the absorbance also increased up to $1 \mathrm{~mL} / \mathrm{min}$, and above this value, the absorbance was decreased because of dispersion. As a result, $1 \mathrm{~mL} / \mathrm{min}$ was selected as the optimum rate (Fig. 9).

\section{Effect of the RC length}

The RC is usually used for mixing the reactants and provided an appropriate time for color development. Variable RC lengths were

Table 1: The optimum conditions for the estimation of NIT using SPR-rFIA

\begin{tabular}{lll}
\hline Parameter & Studied range & Optimum value \\
\hline PHG concentration $(\mathrm{M})$ & $0.01-0.1$ & 0.02 \\
Length of $\mathrm{RC}(\mathrm{cm})$ & $0-200$ & 50 \\
Total flow rate $(\mathrm{mL} / \mathrm{min})$ & $0.73-2.32$ & 1.0 \\
Sample volume $(\mu \mathrm{L})$ & $75-200$ & 150 \\
Ratio of $\mathrm{PbO}_{2}: \mathrm{CAC}(\mathrm{w}:$ & Different ratios & $4: 0.5$ \\
$\mathrm{w}, \mathrm{g})$ & & \\
Length of reactor $(\mathrm{cm})$ & $4.5-8$ & 5.5 \\
Weight of particles $(\mathrm{g})$ & $0.1378-0.2220$ & 0.2220 \\
Size of particles $(\mathrm{mm})$ & $0.3-1.18$ & 1.0 \\
\hline
\end{tabular}

NIT: Nitrazepam, SPR: Solid-Phase Reactor, PHG: Phloroglucinol, CAC: Cellulose acetate, RC: Reaction coil

Table 2: Statistics and analytical values of the calibration graph

\begin{tabular}{ll}
\hline Parameter & Value \\
\hline Regression equation & $\mathrm{y}=0.0025 \mathrm{x}-0.0688$ \\
Correlation coefficient, $\mathrm{r}$ & 0.9993 \\
Linearity percentage, $\mathrm{r}^{2} \%$ & 99.86 \\
Linearity range $(\mu \mathrm{g} / \mathrm{mL})$ & $50-400$ \\
Slope, $\mathrm{b}(\mathrm{mL} / \mu \mathrm{g})$ & $2.49 \times 10^{-3}$ \\
Intercept, a & $6.88 \times 10^{-2}$ \\
Standard deviation of the residuals, $\mathrm{S}_{\mathrm{y} / \mathrm{x}}$ & $1.26 \times 10^{-2}$ \\
Standard deviation of the slope, $\mathrm{S}_{\mathrm{b}}$ & $3.56 \times 10^{-5}$ \\
Standard deviation of the intercept, $\mathrm{S}_{\mathrm{a}}$ & $8.52 \times 10^{-3}$ \\
Sample through-put $\left(\mathrm{h}^{-1}\right)$ & 48 \\
LOD $(\mu \mathrm{g} / \mathrm{mL})$ & 9.23 \\
LOQ $(\mu \mathrm{g} / \mathrm{mL})$ & 30.78 \\
\hline
\end{tabular}

Table 3: Accuracy and precision of the method

\begin{tabular}{llllll}
\hline \multirow{2}{*}{ Sample } & \multicolumn{2}{l}{ Conc. $(\boldsymbol{\mu g} / \mathbf{m L})$ of NIT } & \multirow{2}{*}{ RE (\%)* } & Rec. (\%)* & RSD (\%)* \\
\cline { 2 - 3 } & Added & Found & & & \\
\hline 1 & 100 & 101.12 & 1.12 & 101.12 & 1.95 \\
2 & 150 & 148.85 & -0.77 & 99.23 & 1.93 \\
\hline
\end{tabular}

NIT: Nitrazepam, ${ }^{*}$ Average of five determinations

Table 4: Determination of NIT in the presence of common interferences

\begin{tabular}{llll}
\hline Excipient $(\mathbf{5 0 0} \boldsymbol{\mu g} / \mathbf{m L})$ & \multicolumn{2}{l}{$\begin{array}{l}\text { Concentration of } \\
\text { NIT, } \boldsymbol{\mu g} / \mathbf{m L}\end{array}$} & (Rec. $\mathbf{S S D}) \%$ \\
\cline { 2 - 3 } & Present & Found & \\
\hline Talc & 100 & 101.33 & $101.33 \pm 0.20$ \\
Polyvinylpyrrolidone & & 100.29 & $100.29 \pm 0.31$ \\
Magnesium stearate & & 99.12 & $99.12 \pm 0.46$ \\
Starch & & 101.99 & $101.99 \pm 0.21$ \\
All above additives & & 100.15 & $100.15 \pm 0.50$ \\
\hline NIT: Nitrazepam & & &
\end{tabular}


Table 5: Application of the current and official methods to the estimation of NIT in pharmaceutical forms

\begin{tabular}{|c|c|c|c|c|c|c|}
\hline \multirow[t]{2}{*}{ Pharmaceutical form } & \multicolumn{5}{|l|}{ Proposed method } & \multirow{2}{*}{$\begin{array}{l}\text { Official method } \\
\text { Rec. (\%) }\end{array}$} \\
\hline & Taken conc. $(\mu \mathrm{g} / \mathrm{mL})$ & Found conc. $(\mu \mathrm{g} / \mathrm{mL})$ & Rec. $(\%)^{a}$ & Mean rec. (\%) & $\operatorname{RSD}(\%)^{a}$ & \\
\hline \multirow[t]{2}{*}{ Zipex® tablets (5 mg NIT) } & 150 & 153.19 & 102.13 & 100.89 & 2.98 & 99.67 \\
\hline & 250 & 249.11 & 99.64 & & 1.19 & \\
\hline \multirow{2}{*}{ Mogam $\AA$ tablets (5 mg NIT) } & 150 & 147.48 & 98.32 & 98.73 & 1.93 & 98.10 \\
\hline & 250 & 247.83 & 99.13 & & 1.52 & \\
\hline \multicolumn{2}{|l|}{ Pure NZP } & & & 100.18 & & 100.49 \\
\hline $\mathrm{t}(2.776)^{\mathrm{b}}$ & 0.313 & \multicolumn{2}{|c|}{$\left(n_{1}-1\right)=1,\left(n_{2}-1\right)=1,\left(n_{1}+n_{2}-2\right)=2$} & & & \\
\hline $\mathrm{F}(19.000)^{\mathrm{b}}$ & 1.217 & & & & & \\
\hline
\end{tabular}

${ }^{a}$ Average of five determinations, ${ }^{\mathrm{b}}$ Theoretical value, Conc.: Concentration, RSD: Relative standard deviation, NIT: Nitrazepam

examined in the range of $0-200 \mathrm{~cm}$. The highest absorbance and repeatability were obtained at a length of $50 \mathrm{~cm}$ but were subsequently decreased as the RC increased because of dispersion (Fig. 10)

\section{Effect of sample volume}

Different volumes of injector loop (75 and $200 \mu \mathrm{L})$ were used to study the effect of sample volume. A $150 \mu \mathrm{L}$ volume gave the best response and was used in the subsequent experiments (Fig. 11).

\section{Sampling rate and reactor life-time}

After optimizing all of the manifold and reaction conditions, the appearance of maximum absorbance was $1.25 \mathrm{~min}$. Consequently, the sampling frequency was 48 samples per hour. The repeatability and the lifetime of the proposed reactor were then examined. It was found that the material from the prepared solid phase was still stable more than 1 month and the repeatability of the reactor for 29 successive injections was good (relative standard deviation $[\mathrm{RSD}]<2$ ), with a lifetime $>35$ injections $(\mathrm{RSD} \leq 5)$

\section{Summary of optimum conditions}

The optimized method which was previously used to study the effect of variables on the absorbance of the colour product and the precision of the method was summarized in Table 1.

Calibration graph, accuracy, repeatability, and interference effect A calibration graph was prepared used solutions consisting of $50-400 \mu \mathrm{g} / \mathrm{mL}$ of NIT prepared through suitable dilution of the prepared stock solution. The statistical analytical treatments for the curve and analytical values are summarized in Table 2 . Two different concentrations (five replicates) of NIT were used to establish the accuracy and precision of the rFIA method. The RSD values and recovery indicated that the method provided a good accuracy and repeatability (Table 3).

To assess the usefulness of the method and freedom from interference by tablet additives, recovery testing for NIT was accomplished in the presence of 5-fold additives. Good percentage recoveries were obtained, indicating that no interference was observed and that the method has good selectivity (Table 4).

\section{ANALYTICAL APPLICATIONS}

The present method was effectively used for the determination of NIT in commercial tablets, and the results are given in Table 5. The accuracy of the method was determined by performing recovery test. The obtained recovery values indicated that the suggested method has a good selectivity. In support of evaluating the competence with success of the new method, the results obtained from suggested method were in comparison with those obtained by applying the standard internet protocol (UV method) method [17]. The performance of the proposed methods was judged using two common tests (Student $t$-test and F-test) at $95 \%$ of confidence level
[18], and the result values did not exceed the theoretical values as evident from Table 5 .

\section{CONCLUSION}

The literature survey involved a few flow injection methods for the determination of NIT. Suggested SPR-rFIA spectrophotometric methods have proven to be simple and applicable for the estimation of NIT in its dosage forms. The oxidation of PHG on the $\mathrm{PbO}_{2}$ solidphase reactor which then coupling with reduced NIT drug is fast and sensitive. The method was applied for the determination of NIT in tablets in the presence of other excipients with significant advantages over conventional procedures without any sample pre-treatment or extraction the product.

\section{ACKNOWLEDGMENT}

The authors are thankful to the Department of Chemistry, College of Science, Baghdad University, for providing facilities.

\section{AUTHORS' CONTRIBUTION}

Hind Hadi: Original idea, design of work, data interpretation, and manuscript writing. Mariam Jamal: Preparation of reagents and solutions and execution of experiments. All authors read and approved the final manuscript.

\section{CONFLICT OF INTEREST}

We declare that there is no conflict of interest.

\section{REFERENCES}

1. Tanaka M, Suemaru K, Watanabe S, Cui R, Li B, Araki H. Comparison of short-and long-acting benzodiazepine-receptor agonists with different receptor selectivity on motor coordination and muscle relaxation following thiopental-induced anesthesia in mice. J Pharm Sci 2008;107:277-84.

2. Han S, Li X, Wei B. Silver nanoparticles enhanced chemiluminescence method for the determination of nitrazepam. J Anal Sci 2014;30:495.

3. Thangadurai S, Kanagaraj B, Kulantheswaran M. Reversed-phase high-performance liquid chromatographic method for the simultaneous analysis of four benzodiazepines in pharmaceutical formulations. Malaysian J For Sci 2015;6:12

4. Lee HH, Lee JF, Lin SY, Lin YY, Wu CF, Wu MT, et al. Simultaneous quantification of urine flunitrazepam, nimetazepam and nitrazepam by using liquid chromatography tandem mass spectrometry. Int J Clin Chem 2013;420:134

5. Molaei K, Asgharinezhad AA, Ebrahimzadeh H, Shekari N, Jalilian N, Dehghani Z. Surfactant-assisted dispersive liquid-liquid microextraction of nitrazepam and lorazepam from plasma and urine samples followed by high-performance liquid chromatography with UV analysis. J Sep Sci 2015;38:3905.

6. Tomita M, Okuyama T. Application of capillary electrophoresis to the simultaneous screening and quantitation of benzodiazepines. J Chrom Biom Sci Appl 1996;678:331-7.

7. Bakavoli M, Kaykhaii M. Quantitative determination of diazepam, nitrazepam and flunitrazepam in tablets using thinlayer chromatography-densitometry technique. J Pharm Biom Anal 
2003;31:1185-9.

8. Habibur R. Utilization of eosin dye as an ion pairing agent for determination of pharmaceuticals: A brief review. Int J Pharm Pharm Sci 2017;9:1.

9. Sharma DK, Jasvir S, Pushap R. Spectrophotometric determination of propranolo hydrochloride and metopranol tartrate in pharmaceutical dosage forms, spiked water and biological fluids. Int J Pharm Pharm Sci 2018;10:107.

10. Revanasiddappa HD, Deepakumari HN, Vinay KB. Facile spectrophotometric determination of nimodipine and nitrazepam in pharmaceutical preparations.Anal Univ Bucuresti Chim Anal 2011;20:189.

11. Revanasiddappa HD, Mallegowda SM, Deepakumari HN, Vinay KB. Spectrophotometric determination of nitrazepam and nimodipine in pure and the tablet dosage forms. Asian J Bio Chem Pharm Res 2011;1:70

12. Upadhyay K. Determination of nitrazepam in its pure form, formulations and in biological samples. Recent Res Sci Technol 2012;4:89.

13. Deepakumari HN, Revanasiddappa HD. Spectrophotometric estimation of nitrazepam in pure and in pharmaceutical preparations. J Spectroscopy 2013;2013:1.

14. Al Abachi MQ, Hadi H. Flow injection determination of salbutamol using a solid-phase reactor containing lead (IV) dioxide immobilized. Int J Pharm Chem 2012;2:61-6.

15. Zhang Z, Tang Y. Solid-phase reactor flow-injection on-line oxidizing spectrofluorimetry for determination and dissolution studies of folic acid. Anal Bio Anal Chem 2005;381:932-6.

16. Hadi H, Mouayed M. Determination of clonazepam in pharmaceutical preparations using simple high-throughput flow injection system. J Anal Chem 2017;72:226-33.

17. The Indian Pharmacopoeia. The Indian Pharmacopoeia Commission. Vol. 3. Ghaziabad, ED: The Indian Pharmacopoeia; 2007. p. 834.

18. Hargis LG. Analytical Chem: Principles and Techniques. New Jersey: Pretice-Hall, Inc.; 1998. 